\title{
Clinical factors affecting the pain on injection of propofol
}

\author{
Hye-Joo Kang, Mi-Young Kwon, Byoung-Moon Choi, Min-Seok Koo, Young-Jae Jang, and Myoung-Ae Lee \\ Department of Anesthesiology and Pain Medicine, National Medical Center, Seoul, Korea
}

Background: Pain on propofol injection is a well-known adverse effect. We evaluated the clinical factors that affect the pain on injection of propofol to develop a strategy to prevent or reduce pain.

Methods: We conducted a prospective, observational study of 207 adult patients (ASA I-II), and the patients were classified according to gender, age, the body mass index (BMI), the IV site and the side of the IV site. During the 10 seconds after propofol injection, pain intensity was measured on an 11-point numerical rating scale ( $0=$ no pain and $10=$ worst possible pain). Pain in excess of 3 on the numerical scale was regarded as moderate to severe pain.

Results: The subgroups of gender (female: $55.6 \%$ vs. male: $25.0 \%$; $<<0.01$ ) and the IV site (dorsum of hand: $61.2 \%$ vs. wrist: $40.0 \%$ vs. antecubital fossa: $22.5 \%$; $>0.01$ ) had significantly different frequencies for the incidence of pain on injection on the univariate and multivariate analyses. For the subgroup of females, the incidence of pain was statistically different according to the age group (20-40 yr: $71.0 \%$ vs. $41-60: 54.8 \%$ vs. $61-80: 38.5 \% ; \mathrm{P}=0.014)$.

Conclusions: Our results showed that the younger age patients, the patients with a peripheral IV site and female patients are more sensitive to pain on the injection of propofol. (Korean J Anesthesiol 2010; 58: 239-243)

Key Words: Clinical medicine, Pain, Propofol, Sex differences.

\section{Introduction}

Propofol is a popular intravenous (IV) anesthetic drug, used for induction and maintenance during general anesthesia owing to its rapid onset and short duration. However, the incidence of pain following propofol injection is seen in approximately $70 \%$ of patients, in the absence of other pretreatments [1-3]. The nature of pain was described as extremely sharp, aching or burning. It has been ranked as the seventh most important drawback in current practice of clinical anesthesia by American anesthesiologists [4]. The mechanism by which propofol induces pain on injection has remained unclear, but many factors that affect pain on injection are evaluated. Not only the intrinsic drug property (e.g. emulsion composition, $\mathrm{pH}$ of the formulation, temperature, injection volume and osmolarity) ,but the injection procedure itself could contribute to injection pain [5-7], which includes the speed of pushing the medication during injection, propofol concentration in the aqueous phase, speed of IV carrier fluid, use of local anesthetics, and the buffering effect of blood $[6,8,9]$. In addition to this, many

Received: November 25, 2009. Revised: 1st, December 16, 2009; 2nd, January 5, 2010. Accepted: January $29,2010$.

Corresponding author: Mi-Young Kwon, M.D., Department of Anesthesiology and Pain Medicine, National Medical Center, 243, Ulgiro 6-ga, Junggu, Seoul 100-799, Korea. Tel: 82-2-2260-7372, Fax: 82-2-2260-6961, E-mail: mykwon.nmc@gmail.com

(c) This is an open-access article distributed under the terms of the Creative Commons Attribution Non-Commercial License (http:// creativecommons.org/licenses/by-nc/3.0/), which permits unrestricted non-commercial use, distribution, and reproduction in any medium, provided the original work is properly cited. 
pretreatment agents have also been evaluated for prevention or reduction of the pain that accompanies propofol injection. There is a need to evaluate the clinical factors that affect the pain on propofol injection in each patient. However, till date, there is relatively very little published data on the clinical factors that affect the injection pain of propofol without pretreatment. Thus, we evaluated the clinical factors affecting the incidence of pain on propofol injection in patients scheduled for elective surgery.

\section{Materials and Methods}

The study was performed in 207 patients (ASA physical status I-II, aged 20-80 yr) undergoing elective surgery after receiving study approval by institutional review board (IRB) and informed consent from patients. Patients having problems in communication or psychological disorders, patients on analgesics or sedative were excluded from this study s. The body mass index (BMI) was calculated after measuring height and body weight of patients and was classified according to the cut-off points for Asian population as underweight (less than $\left.18.5 \mathrm{~kg} / \mathrm{m}^{2}\right)$; normal weight $\left(18.5-23.9 \mathrm{~kg} / \mathrm{m}^{2}\right)$; overweight $\left(23.0-27.49 \mathrm{~kg} / \mathrm{m}^{2}\right)$; and obese $\left(27.5 \mathrm{~kg} / \mathrm{m}^{2}\right.$ or higher)[10]. No patients had received premedication before their arrival in the operating room or received analgesics within 24 hours before surgery. An 18-gauge catheter was inserted at approximately 120 minutes before induction of anesthesia for venous access and was classified depending on the insertion site as dorsum of the hand, wrist or antecubital fossa, and the side of IV site as patient's dominant hand side or not. All drugs were prepared and stored at room temperature and used within 30 minutes of preparation. The induction dose of propofol was $2 \mathrm{mg} / \mathrm{kg}$. On arrival in the operating room, patients were routinely monitored and received $0.5 \mathrm{mg} / \mathrm{kg}$ of propofol (1.0\%/12 ml ampoule, Pofol $^{\circledR}$, Jeil Pharm) by $0.3 \mathrm{ml} / \mathrm{sec}$ through the IV cannula with closed infusion line. During first 10 seconds after receiving first dose of propofol patients were asked standard questions regarding their comfort or pain during the injection. Pain intensity was measured on an 11-point pain intensity numerical rating scale (PI-NRS), where $0=$ no pain and $10=$ worst pain possible. Based on previously published data, pain of moderate to severe intensity was assessed if the PI-NRS score was found to be more than 3 [11]. Induction of anesthesia was continued with the $1.5 \mathrm{mg} / \mathrm{kg}$ of propofol. After patients lost consciousness, rocuronium $0.6 \mathrm{mg} / \mathrm{kg}$ was given to facilitate muscle relaxation and tracheal intubation, and anesthesia was maintained with sevoflurane $1.0 \%$ to $3.0 \%$ and nitrous oxide $50 \%$ in oxygen with controlled ventilation. Fentanyl was administered only after induction of anesthesia. Within 24 hours after operation, a researcher blinded to this study checked the injection site for pain, edema, wheal, flare response or any other adverse effect. All statistical analyses were performed using SPSS software (version 12.0, SPSS Inc., IL, USA). Values are expressed as mean \pm standard deviation (SD). Univariate statistical analysis was carried out using Student t-test and Chi-Square test to compare demographic data and incidence of propofol injection pain. Multivariate analysis for factors affecting injection pain performed stepwise logistic regression. Independent factors that had statistical significance or were close to this figure after univariate analysis were selected for the multivariate analysis. All tests were 2 -sided and a value of $\mathrm{P}<0.05$ was considered statistically significant.

\section{Results}

The results of pain on propofol injection were based on data derived from study on a total of 207 patients. Demographic data of patients were shown in Table 1 . The incidence of pain was estimated from the ratio of patients experiencing pain on injection (PI-NRS $>3$ ) to all patients in each group. Table 2 displays incidence of pain on injection, univariate and multivariate analyses of factors affecting the incidence of pain on injection. It was observed that female gender and dorsum of hand in IV site had a significantly greater frequency of pain on injection on the univariate analysis. Side of IV site (dominant hand side or not), BMI and age did not correlate significantly with the incidence of pain on injection. The factors that were associated independently with the incidence of pain on injection were gender and IV site according to the multivariate analysis (logistic regression model). Table 3 contains the distribution of patients by independent factors. The distribution of subgroups in each gender group were not statistically different with respect to age and IV site (male: $\mathrm{P}=0.42$; female: $\mathrm{P}=0.78$ ). The peripheral IV site groups showed higher incidence of pain on injection in both gender groups $(\mathrm{P}<0.01)$. In a subgroups of female patients, the incidence of pain was significantly different by age group (20-40 yr: $71.0 \%$ vs. $41-60: 54.8 \%$ vs. $61-80$ : $38.5 \%$; $\mathrm{P}=0.014$ ). The higher incidence of pain on injection was seen in younger groups. In the subgroups of males, the incidence of pain was however, not different among the different age groups (20-40 yr: $23.4 \%$ vs. $41-60: 27.8 \%$ vs. $61-80: 24.0 \%$; $\mathrm{P}=0.89$ ).

Table 1. Patients Demographics $(n=207)$

\begin{tabular}{lc} 
Age (years) & $46.9 \pm 16.4$ \\
Gender (Male : Female) & $108: 99$ \\
Height $(\mathrm{cm})$ & $163.3 \pm 9.6$ \\
Weight $(\mathrm{kg})$ & $64.2 \pm 10.6$ \\
\hline
\end{tabular}

Values are expressed as mean \pm standard deviation, except gender. 
Table 2. Univariate and Multivariate Analysis of Factors Affecting the Incidence of Pain on Propofol Injection

\begin{tabular}{|c|c|c|c|c|}
\hline \multirow{2}{*}{ Factors (n) } & \multicolumn{2}{|c|}{ Univariate analysis } & \multicolumn{2}{|c|}{ Multivariate analysis } \\
\hline & Incidence of pain & P value & Odds ratio (95\% C.I.) & $\mathrm{P}$ value \\
\hline Gender & & $<0.01$ & & $<0.01$ \\
\hline Male (108) & $25.0 \%$ & & 1.0 (reference) & \\
\hline Female (99) & $55.6 \%$ & & $3.90(2.06-7.38)$ & \\
\hline Age (yr) & & 0.39 & & 0.21 \\
\hline $20-40(78)$ & $42.3 \%$ & & $2.09(0.91-4.80)$ & \\
\hline $41-60(78)$ & $42.3 \%$ & & $1.44(0.63-3.27)$ & \\
\hline $61-80(51)$ & $31.4 \%$ & & 1.0 (reference) & \\
\hline IV site & & $<0.01$ & & $<0.01$ \\
\hline Antecubital fossa (80) & $22.5 \%$ & & 1.0 (reference) & \\
\hline Wrist (65) & $40.0 \%$ & & $2.02(0.95-4.31)$ & \\
\hline Dorsum of hand (62) & $61.2 \%$ & & $5.31(2.44-11.59)$ & \\
\hline $\mathrm{BMI}\left(\mathrm{cm} / \mathrm{kg}^{2}\right)$ & & 0.97 & Not analyzed & \\
\hline$<18.5(4)$ & $50.0 \%$ & & & \\
\hline $18.5-22.9(80)$ & $40.0 \%$ & & & \\
\hline $23.0-27.49(88)$ & $38.6 \%$ & & & \\
\hline$>27.5$ (35) & $40.0 \%$ & & & \\
\hline Side of IV site & & 0.83 & Not analyzed & \\
\hline Dominant hand (94) & $40.4 \%$ & & & \\
\hline Non-dominant hand (113) & $38.9 \%$ & & & \\
\hline
\end{tabular}

Table 3. Incidence of Pain* on Injection and the Distribution of Patients

\begin{tabular}{lccc}
\hline \multirow{2}{*}{ IV site } & \multicolumn{3}{c}{ Age (yrs) } \\
\cline { 2 - 4 } & $20-40$ & $41-60$ & $61-80$ \\
\hline Male $(\mathrm{n}=108)^{\ddagger}$ & & & \\
Dorsum of hand & $40.0 \%$ & $54.5 \%$ & $42.8 \%$ \\
& $10(9.3 \%)$ & $11(10.2 \%)$ & $7(6.5 \%)$ \\
Wrist & $29.4 \%$ & $20.0 \%$ & $25.0 \%$ \\
Antecubital fossa & $17(15.7 \%)$ & $10(9.3 \%)$ & $4(3.7 \%)$ \\
& $20(18.5 \%)$ & $15(13.9 \%)$ & $14(13.0 \%)$ \\
Female (n=99) ${ }^{\ddagger} \S$ & & & $14.3 \%$ \\
Dorsum of hand & $80.0 \%$ & $70.6 \%$ & $71.4 \%$ \\
& $10(10.1 \%)$ & $17(17.2 \%)$ & $7(7.1 \%)$ \\
Wrist & $70.0 \%$ & $50.0 \%$ & $40.0 \%$ \\
Antecubital fossa & $63.6 \%$ & $36.4 \%$ & $11.1 \%$ \\
& $11(11.1 \%)$ & $11(11.1 \%)$ & $9(9.1 \%)$ \\
\hline
\end{tabular}

$*_{\%}$, patients experiencing pain on injection (pain intensity numerical rating scale $>3),{ }^{\dagger}$ Number (\%) among the same gender patients. ${ }^{\ddagger} \mathrm{P}<0.01$ intergroup comparison among IV site subgroups, ${ }^{\S} \mathrm{P}=0.014$ intergroup comparison among age groups.

\section{Discussion}

Propofol has been widely used for induction and maintenance of anesthesia, but pain that accompanies propofol injection can be very distressing to the patients [6]. Until now, the mechanism of pain following propofol injection has been unclear. Propofol belongs to the group of phenols that can directly irritate the skin, mucous membrane and venous intima and could immediately stimulate nociceptors and free nerve endings [12]. The concentration of aqueous free propofol is related to injection pain. By its indirect action on the endothelium, it was suggested that propofol activates the kallikrein-kinin system and releases bradykinin, thereby producing venous dilation and hyperpermeability, which increases the contact between aqueous phase of propofol and free nerve endings, results in delayed pain within half a minute $[8,13]$. Recently several studies have suggested that propofol had no effect on the concentration of bradykinin in plasma, compared with saline control group [14,15].

Strategies to reduce the pain on injection includes addition of lidocaine, cooling or diluting the propofol solution, and pretreatment with lidocaine, ephedrine, ondansetron, metoclopramide, nafamostat mesilate, opioids, thiopental, or ketamine $[1,2,12,16-20]$. The most frequently used analgesic method 
is IV lidocaine $(0.5 \mathrm{mg} / \mathrm{kg})$ on the antecubital fossa, given as a Bier's block, 30 to 120 seconds before the injection of propofol [1].

The incidence and the severity of pain following propofol injection is directly related to site of injection and smaller size of the vessels [8]. In children, younger the age, higher is the incidence and severity of pain on propofol injection [21] attributable to the smaller size of vein in younger children. The present study also pointed out that incidence of pain on propofol injection was different between the different IV sites, and the highest frequency was observed in dorsum of hand. This finding is consistent with the previously published studies $[9,13,22]$. The injection procedure itself affects the incidence and severity of pain on injection, the pain can be reduced by the injection of propofol into the vein of antecubital fossa [8, 9]. However, it is not feasible to recommend all anesthetists to choose the antecubital fossa vein to avoid propofol injection pain as the IV site in antecubital fossa is relatively uncomfortable to patients and has a tendency to occlude.

In a study conducted to examine the influence of aging on lidocaine requirements for propofol-induced pain, the elderly patients needed relatively small dose of lidocaine to reduce the pain compared with the young patients [23]. In our study, the significant differences and the downward tendency with age were observed in the pain incidence of female patients. The exact reason for this difference is not known, but it could be because of the aging influence on pain thresholds [3,24].

Till date, the relationship between gender and propofol injection pain needs to be established. It has been accepted that there is no gender difference in the incidence of pain on propofol injection without any specific references or targeted research work $[3,23]$. Therefore, this study evaluated the differences in pain incidence between male and female. Gender is the baseline data in any research for selecting or distributing the patients, and this gender related bias is an important demographic parameter that is observed during conduct of any clinical study. The present study showed that male patients had lower incidence of injection pain than female patients. Propofol is distributed in two phases with an outer aqueous phase and an inner lipid phase in the propofol emulsion preparation. Only the outer aqueous phase comes into contact with intima of the vein, so the concentration of an irritating agent in the aqueous phase is considered to the main cause of pain due to propofol injection [6,25]. The proposed reason of gender difference in propofol-induced pain is firstly due to the mechanical effect that male has larger sized veins than female while another factor suggested is the difference of pain sensitivity observed between the gender and this emphasizes the necessity of specifying the patients' gender while investigating propofol-associated withdrawal. Clinically, it is a fact that female experiences greater pain intensity, with or without related distress, and shows heightened sensitivity to experimentally induced pain compared to that of males [26-30]. Further analysis is needed to evaluate the relationship between gender and pain-related variables. Continued research at the genetic and receptor levels may support the need to develop gender-specific drug therapies [29].

Our finding must be considered within the context of the study limitation. First, the patients were not assigned to subgroups by randomization. Second, the sample size for subgroup was relatively small. Third, the comparison for pain intensity with pretreatment was not evaluated. Further studies should consider these limitations and evaluate other possible factors that could affect the injection pain, and develop strategies for preventing or reducing the pain on injection of propofol, considering the factors such as drug property, kinds of pretreatment and procedure and associated clinical factors.

Propofol induced pain is a common problem during induction of general anesthesia. Our results showed that the younger age patients, the patients with a peripheral IV site and female patients are more sensitive to pain following IV injection of propofol. Therefore clinicians need to have strategies to reduce or prevent the pain for patients, who have factors affecting the pain on injection of propofol.

\section{References}

1. Picard P, Tramer MR. Prevention of pain on injection with propofol: a quantitative systematic review. Anesth Analg 2000; 90: 963-9.

2. Nathanson MH, Gajraj NM, Russell JA. Prevention of pain on injection of propofol: a comparison of lidocaine with alfentanil. Anesth Analg 1996; 82: 469-71.

3. Tan CH, Onsiong MK. Pain on injection of propofol. Anaesthesia 1998; 53: 468-76.

4. Macario A, Weinger M, Truong P, Lee M. Which clinical anesthesia outcomes are both common and important to avoid? The perspective of a panel of expert anesthesiologists. Anesth Analg 1999; 88: 1085-91.

5. Klement W, Arndt JO. Pain on i.v. injection of some anaesthetic agents is evoked by the unphysiological osmolality or $\mathrm{pH}$ of their formulations. Br J Anaesth 1991; 66: 189-95.

6. Klement W, Arndt JO. Pain on injection of propofol: effects of concentration and diluent. Br J Anaesth 1991; 67: 281-4.

7. Brazeau GA, Cooper B, Svetic KA, Smith CL, Gupta P. Current perspectives on pain upon injection of drugs. J Pharm Sci 1998; 87: 667-77.

8. Scott RP, Saunders DA, Norman J. Propofol: clinical strategies for preventing the pain of injection. Anaesthesia 1988; 43: 492-4.

9. McCulloch MJ, Lees NW. Assessment and modification of pain on induction with propofol (Diprivan). Anaesthesia 1985; 40: 1117-20.

10. Appropriate body-mass index for Asian populations and its implications for policy and intervention strategies. Lancet 2004; 363: 157-63.

11. Collins SL, Moore RA, McQuay HJ. The visual analogue pain 
intensity scale: what is moderate pain in millimetres? Pain 1997; 72: 95-7.

12. Ambesh SP, Dubey PK, Sinha PK. Ondansetron pretreatment to alleviate pain on propofol injection: a randomized, controlled, double-blinded study. Anesth Analg 1999; 89: 197-9.

13. Briggs LP, Clarke RS, Dundee JW, Moore J, Bahar M, Wright PJ. Use of di-isopropyl phenol as main agent for short procedures. Br J Anaesth 1981; 53: 1197-202.

14. Lee EH, Lee SH, Park DY, Ki KH, Lee EK, Lee DH, et al. Physicochemical properties, pharmacokinetics, and pharmacodynamics of a reformulated microemulsion propofol in rats. Anesthesiology 2008; 109: 436-47.

15. Sim JY, Lee SH, Park DY, Jung JA, Ki KH, Lee DH, et al. Pain on injection with microemulsion propofol. Br J Clin Pharmacol 2009; 67: 316-25.

16. Saadawy I, Ertok E, Boker A. Painless injection of propofol: pretreatment with ketamine vs thiopental, meperidine, and lidocaine. Middle East J Anesthesiol 2007; 19: 631-44.

17. Nakane M, Iwama H. A potential mechanism of propofol-induced pain on injection based on studies using nafamostat mesilate. Br J Anaesth 1999; 83: 397-404.

18. McCrirrick A, Hunter S. Pain on injection of propofol: the effect of injectate temperature. Anaesthesia 1990; 45: 443-4.

19. Cheong MA, Kim KS, Choi WJ. Ephedrine reduces the pain from propofol injection. Anesth Analg 2002; 95: 1293-6.

20. Agarwal A, Ansari MF, Gupta D, Pandey R, Raza M, Singh PK, et al. Pretreatment with thiopental for prevention of pain associated with propofol injection. Anesth Analg 2004; 98: 683-6.
21. Cameron E, Johnston G, Crofts S, Morton NS. The minimum effective dose of lignocaine to prevent injection pain due to propofol in children. Anaesthesia 1992; 47: 604-6.

22. Hannallah RS, Baker SB, Casey W, McGill WA, Broadman LM, Norden JM. Propofol: effective dose and induction characteristics in unpremedicated children. Anesthesiology 1991; 74: 217-9.

23. Fujii Y, Shiga Y. Influence of aging on lidocaine requirements for pain on injection of propofol. J Clin Anesth 2006; 18: 526-9.

24. Gil KM, Ginsberg B, Muir M, Sykes D, Williams DA. Patient-controlled analgesia in postoperative pain: the relation of psychological factors to pain and analgesic use. Clin J Pain 1990; 6: 137-42.

25. Doenicke AW, Roizen MF, Rau J, Kellermann W, Babl J. Reducing pain during propofol injection: the role of the solvent. Anesth Analg 1996; 82: 472-4.

26. Uchiyama K, Kawai M, Tani M, Ueno M, Hama T, Yamaue H. Gender differences in postoperative pain after laparoscopic cholecystectomy. Surg Endosc 2006; 20: 448-51.

27. Paller CJ, Campbell CM, Edwards RR, Dobs AS. Sex-based differences in pain perception and treatment. Pain Med 2009; 10: 289-99.

28. Ueno K. Gender differences in pharmacokinetics of anesthetics. Masui 2009; 58: 51-8.

29. Wiesenfeld-Hallin Z. Sex differences in pain perception. Gend Med 2005; 2: 137-45.

30. Mencke T, Beerhalter U, Fuchs-Buder T. Spontaneous movements, local reactions and pain on injection of rocuronium. A comparison between female and male patients. Acta Anaesthesiol Scand 2001; 45: 1002-5. 